\title{
Effect of cold expansion on improving of fatigue initiation life in Aluminium alloy
}

\author{
Mohamed El Habiri, Mustapha Benachour*, Nadjia Benachour \\ University of Tlemcen, Ingeniery of Mechanical Systems and Materials Laboratory, Tlemcen, Algeria \\ Faculty of Technology, Mechanical Engineering Department \\ yacine2704@gmail.com,.bmf_12002@yahoo.fr,nbenachour2005@yahoo.fr
}

ABSTRACT. In this paper, numerical investigation was carried out to quantify the effect of the cold expansion on fatigue crack initiation in Aluminium alloy. The improvement in fatigue initiation life of specimen after the cold expansion process was investigated with the drilled hole of 2024 T351 Aluminium alloy plate. The applied degree of expansion (DCE $\%=100$ (Dd) $/$ d) is $4.6 \%$ where the effect of friction $(\mu=0.2)$ is considered. Residual stress field is determined using 3D Finite Element Analysis and shows the presence of compressive residual stress around the hole. The results showed a high compressive residual stress near the hole in exit face of the hole and at middle of the plate thickness around the hole. Local strain approach is applied in evaluation of fatigue initiation lives under Afgrow environment code. Fatigue initiation lives are improved by the presence of the compressive residual stresses comparatively to the drilled hole without of compressive residual stresses. Also, the fatigue initiation lives are increased with the increase in stress ratio for drilled hole and expanded hole

KEYWORDS. Fatigue crack initiation; Cold expansion; Compressive residual stress; Stress ratio; Aluminium alloy.

\section{INTRODUCTION}

$\mathrm{P}$ reventing fatigue failures in aircraft structures is a principle aiming of aircraft designers and maintainers. The need to prevent fatigue failures and extended the fatigue life, improvement methodologies are necessaries. Fatigue phenomenon presents an essential failure mode in aircraft structures. The percentage of failure varies from 55 to

$61 \%$ [1] in aeronautic components. In aircraft structures, the joints are carried out by mechanically fastened joints, adhesively and bonded joints. In fastened joints is necessary to improve the quality of holes by introducing compressive residuals stresses. The method to introduce the compressive residuals stress are such as shot peening [2,3] laser shock [4, 5], and cold expansion [6-9]. 
Fatigue phenomenon undergoes several stages and from an engineering point of view it is convenient to divide the fatigue life of a structure into three stages [10]: fatigue crack initiation, stable of crack growth and unstable crack growth. Fatigue crack initiation presents the main stage in fatigue life which has been extensively studied [11,12]. Different approaches will be used for estimation of fatigue crack initiation life has been applied by many researchers [13, 14], which is based essentially on stress concentration factor and local stress-strain concepts. Others researchers have used the equivalent strain-energy density method to predict fatigue crack initiation [12,15]. These works assumed that crack growth part of fatigue life is small comparatively to the initiation fatigue life. In initiation phase, fatigue life is linked strongly to metallurgical, geometrical, loading parameters and stress state without external loading (presence of residual stress).

The main loading parameter under constant applied load is stress ratio (mean stress effect) investigated by several researchers, principally in stable crack propagations on some materials [16, 17]. Effect of stress ratio on fatigue crack initiation from hole without residual stress was investigated by Fujczak [18]. It is noticed that an increase in the R-ratio decreases the number of cycles to initiate a fatigue crack. In study conducted by Ranganathan et al [19], crack initiation phase has been considered in the estimation of total fatigue life when short crack growth approach has been applied. The results on fatigue crack initiation of $2024 \mathrm{~T} 351 \mathrm{Al}$-alloy shows an increasing in initiation life with increasing in stress ratio and maximum remote stress in absence of residuals stresses.

Fatigue life depends essentially on zone of compressive residuals stresses around the hole. These stresses decrease the effect of external applied stress field and tend to delay crack growth rate and increase the fatigue life. To quantify cold expansion effects on fatigue crack initiation and propagation, Amrouche et al. [20] have conducted experimental and numerical investigation on 6005 Al-alloy plate. It was found that the compressive residual stresses induced by the cold expansion process are the important parameter for the improvement of fatigue initiation life. Also, it was shown that the fatigue initiation life increases with increasing in the degree of cold expansion and depend on compressive residuals stress zones [20, 21]. In study conducted by Gopalakrishna et al. [22], two cold expansion techniques were applied to generate compressive residuals stress around hole, as split-sleeve with taper pin and split-sleeve with ball. It was concluded that split-sleeve with tapered pin technique gives higher compressive residuals stress comparatively to split-sleeve with ball technique. The improvement in fatigue life was also found to be maximal at $5 \%$ degree of expansion, at which the fatigue life is 5.3 times higher than the non-expanded holes. The same tendency was confirmed by others researchers [22-25]. In experimental fatigue investigation of Chandawanich and Sharpe [23] of cold worked hole in $7075 \mathrm{~T} 6 \mathrm{Al}$-alloy plate, they consider initiation stage corresponded to crack approximately $0.1 \mathrm{~mm}$ long. The fatigue initiation lives are too large comparatively to the non-cold-worked hole for all level of applied external load.

Additionally to the changes of compressive residuals stress along the plate thickness from entrance face to exit face in cold expansion process, distribution of compressive residuals stress and fatigue lifetime is affected also by variation of plate thickness [26]. In combined numerical/experimental study, Chakherlou and Vogwell [27] have investigated the effect of residual stress induced by cold expansion process of hole on fatigue life failure of $7075 \mathrm{~T} 6 \mathrm{Al}$-alloy plate. A 3D finite element model was used to simulate cold expansion. In FE modelling, 8-node linear isoparametric cubic elements were used for the pin and the plate. The fatigue results show the improvement in fatigue life in cold expanded hole of specimens comparatively to the drilled specimens. The improvement in fatigue life is almost 10 times.

Liu et al [28] have used cold expansion with a split sleeve to produce residuals stress fields. They have performed numerical simulations using 3D finite element modelling. The friction effect was included in this investigation by using the elastic coulomb friction with a friction coefficient $\mu=0.1$ also primary included by Chakherlou and Vogwell [27]. Also, Liu et al. [28] have studied the effect of cold expansion on prediction of fatigue life using respectively SWT model [29] and WB model [30]. It was concluded that WB model give a better result than the SWT model. Kurhade et al. [31] conducted 3D finite element analysis for plane stress, where the effect of strain hardening was investigated on the distribution of residuals stress induced by new method called "CsSmPCx process: sleeve with split mandrel and pilot cold expansion" on 7050-T7451 aluminium alloy. From this process the residual stresses along the plate front and back edges decreases with some rise in the tensile stresses away from the hole edge. As for the increase in fatigue amelioration of hole with cold expansion process, Liu et al. [32] reported that, the fatigue life was improved by a factor from 1.5 to 5.0 witch depend on the expansion level. Also, in work of Semari et al. [6], the effects of residuals stresses induced by ball in cold expansion process on fatigue life of $6082 \mathrm{~T} 6$ are given by experimentally and numerically investigation (3D finite element analysis). Improvement in fatigue life by expansion was shown under increasing of degree of expansion.

The aiming of this paper is to evaluate the residual stress field induced by cold expansion process around hole in the first hand. On the other hand, we investigate the effects of compressive residuals stresses around the hole on improving of fatigue crack initiation life using local strain approach in 2024 T351 of Al-alloy plate. Also, the effect of stress ratio is highlighted. 


\section{FINITE ELEMENT MODELING}

A

3D Finite element model was used to simulate cold expansion process using ANSYS code [33]. Tetrahedral element with four nodes was used for the mesh of the holed plate. It is a common practice in the industry to use automatic tetrahedral mesh generators to discretize complex three-dimensional structural components. This type of mesh generators can handle very complex geometries with a minimum of human intervention (as compared to, e.g., the manual generation of a mesh of hexahedral elements) [34, 35]. Oñate et al [36] have used linear tetrahedral element in finite element analysis for evaluation of pressure and plastic strain distribution where numerical solution is improved [36]. The linear tetrahedral element is robust in contact analysis, the element matrices are inexpensive to calculate, and the resulting global stiffness matrix has a relatively small bandwidth $[37,38]$. The applied of a large and complex analysis model with hexahedral finite elements is a much more difficult task than with tetrahedral elements [39]. Also, for tapered pin, eight-node structural solid elements (Solid 185) were used with reduced integration. Less computation time presents required advantage of these elements. Additionally, eight node surface-to-surface contact (CONTA174) and (TARGE170) elements were generated to model the surface-to-surface contact. These contact elements allow the pressure to be transferred between the contacting surfaces and prevents them from penetrating each other [27]. Due to double symmetry with respect to the $\mathrm{X}-\mathrm{Z}$ and $\mathrm{Y}-\mathrm{Z}$ planes, a quarter of the plate and pin were modelled. In addition to the boundary constraints along the planes of symmetry, the plate was constrained in the $Z$ direction at the exit face nodes.

The dimension of the plate are $6.32 \mathrm{~mm}$ in thick, $25 \mathrm{~mm}$ wide and $40 \mathrm{~mm}$ long witch corresponds to the central part of the fatigue specimens (Fig. 1). The hole diameter " $\mathrm{d}$ " is $5 \mathrm{~mm}$ and the largest diameter of the tapered pin " $\mathrm{D}$ " is $5.23 \mathrm{~mm}$ which produces a $4.6 \%$ degree of expansion $(D C E \%=100 \times(D-d) / d)$. In published paper, several researchers have ignored friction in cold expansion process [9, 40], although introduced by others [27, 41]. The friction effect was included in this work using elastic coulomb fraction with $\mu=0.2$. An elastic-plastic material relationship was used to represent the aluminium alloy 2024 T351 with isotropic hardening. The stress-strain curve is shown on Fig. 2 and mechanical properties are summarised in Table 1. A linear elastic material relationship was assumed for the steel pin with Young's modulus of $210 \mathrm{GPa}$ and Poisson's ratio of 0.3 .

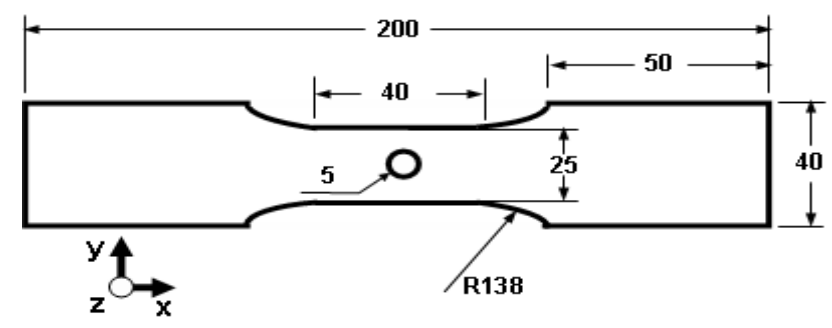

Figure 1: Geometrical model of fatigue specimen

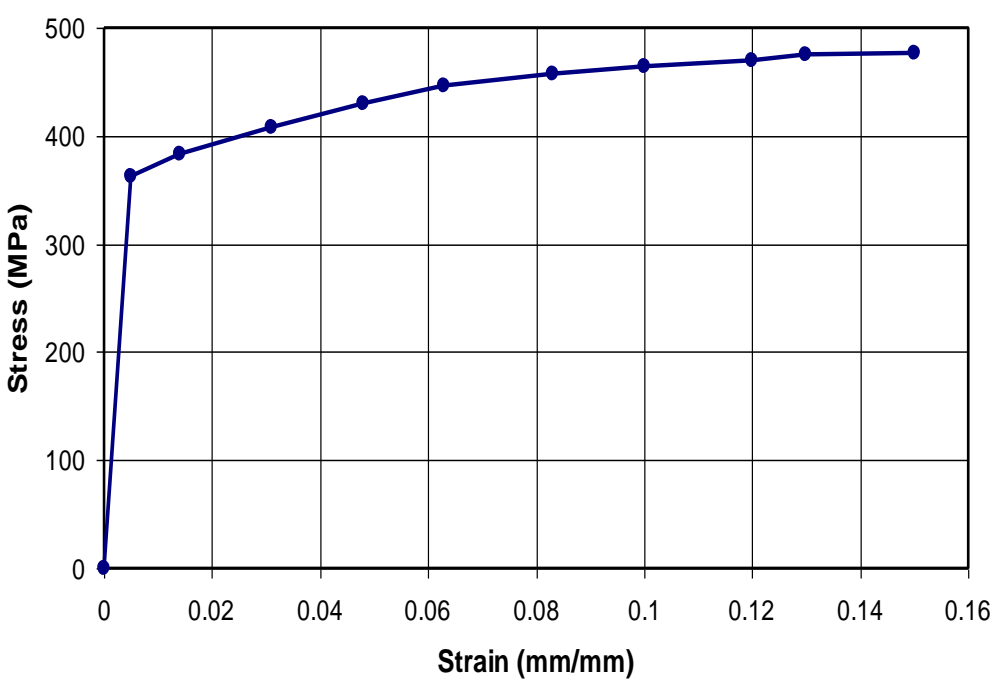

Figure 2: True strain-stress curve of 2024 T351 Al-alloy. 


\begin{tabular}{cccc}
\hline $\mathrm{E}(\mathrm{GPa})$ & $\sigma_{\mathrm{e}}(\mathrm{MPa})$ & $\mathrm{UTS}(\mathrm{MPa})$ & $v$ \\
74.08 & 363 & 477 & 0.33 \\
\hline
\end{tabular}

Table 1: Mechanical properties of 2024 T351 Al-alloy.

The tapered pin as shown in Fig $3 \mathrm{a}$ was positioned near the hole at the entrance face (Fig $3 \mathrm{~b}$ ). The simulation of cold expansion was carried out by incrementing the position of the nodes in the pin upper face in the $-Z$ direction. Fig. $3 b$ shows the meshed model with fixed and symmetric boundary conditions. The inner surface of the hole was then subjected to incremental pressure loading since the tapered mandrel was considered in this study.
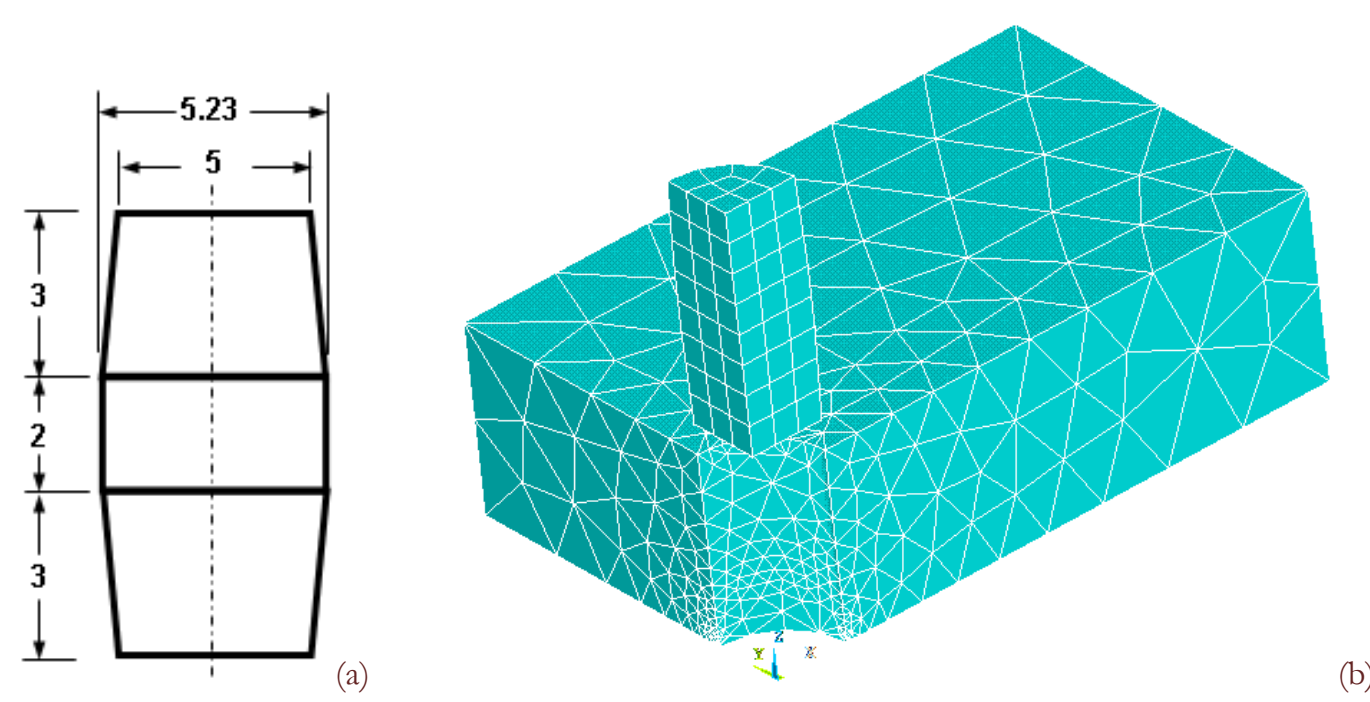

Figure 3: Cold expansion process a) Detail of tapered pin used for cold expansion, b) Mesh using 3D finite element model.

\section{RESIDUALS STRESSES DISTRIBUTION DUES TO COLD EXPANSION}

he cold-expansion simulation shows the hoop stress evolution around the hole during the loading and unloading steps (entrance and exit of mandrel through the hole). During the loading phase, the level of the compressive residual stress is achieved with few steps witch the mandrel improves the plastic radius up to a maximum value generated at a maximum nominal interference. In unloading phase, the elastic-plastic release of the plate generates the reverse-yielding zone. Identification of the accurate residual stress profile around a cold expanded hole is critical due to related of the level and distribution of the residual stress on fatigue performance of the hole. It is recognized that magnitude and distribution of the residual stress is directly related to the fatigue performance of the hole. So, the residual compressive stress generated around the hole has the effect of reducing the stress concentration after the application of tensile cyclic loads to the fastener hole (maximum stress at hole) and therefore reduces the effective stress intensity factors for growth of cracks emanating from the hole [42]. The residual stress field with $4.6 \%$ in the degree of cold expansion is presented in Fig. 4 respectively in entrance, mild and exit faces of the hole. The path of these residual stress profiles extends from the edge of the hole to the free edge of the plate, along the $\mathrm{X}$-axis shown in Fig. 1. This is the critical plane for fatigue crack growth assuming the plate is axially loaded in the longitudinal direction (Y-axis). The curves in Fig. 4 show compressive residuals stresses within about $2.8 \mathrm{~mm}$ from the hole edge at the entrance face location, but in midplane position is about $2.4 \mathrm{~mm}$. So, at exit face, the length of compressive residuals from hole is about $3.8 \mathrm{~mm}$. Also it is noticed that maximum compressive residuals stresses at entrance face is about $100 \mathrm{MPa}$. These stresses increase in midplane and exit face positions and are respectively $390 \mathrm{MPa}$ and $410 \mathrm{MPa}$ which is greater than the yield stress of $363 \mathrm{MPa}$ [42]. After $4 \mathrm{~mm}$ position, the residuals stresses are tensile for all position through thickness. Additionally to the effect of cold expansion on circumferential residuals stresses, Fig. 5 shows also, the effect of cold expansion on Von Mises 
equivalents stresses SQV. The figure reveals the significant difference between the equivalent stress at exit and entry surfaces. These stresses decrease and present constants variations from $6 \mathrm{~mm}$ to the expanded hole. Also, the equivalent stress field at the exit surface is dramatically increased witch is shown after the exit of the pin (Fig. 6.c).

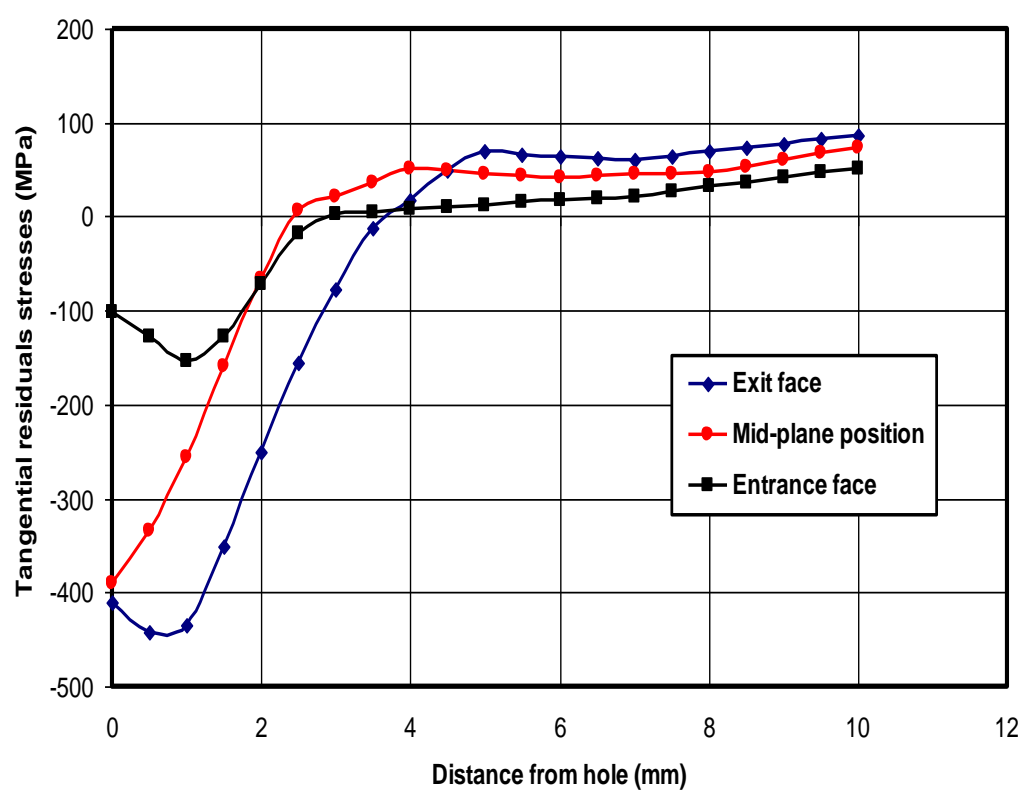

Figure 4: Tangential residual stress at different through-thickness positions for $6.32 \mathrm{~mm}$ in thick of plate.

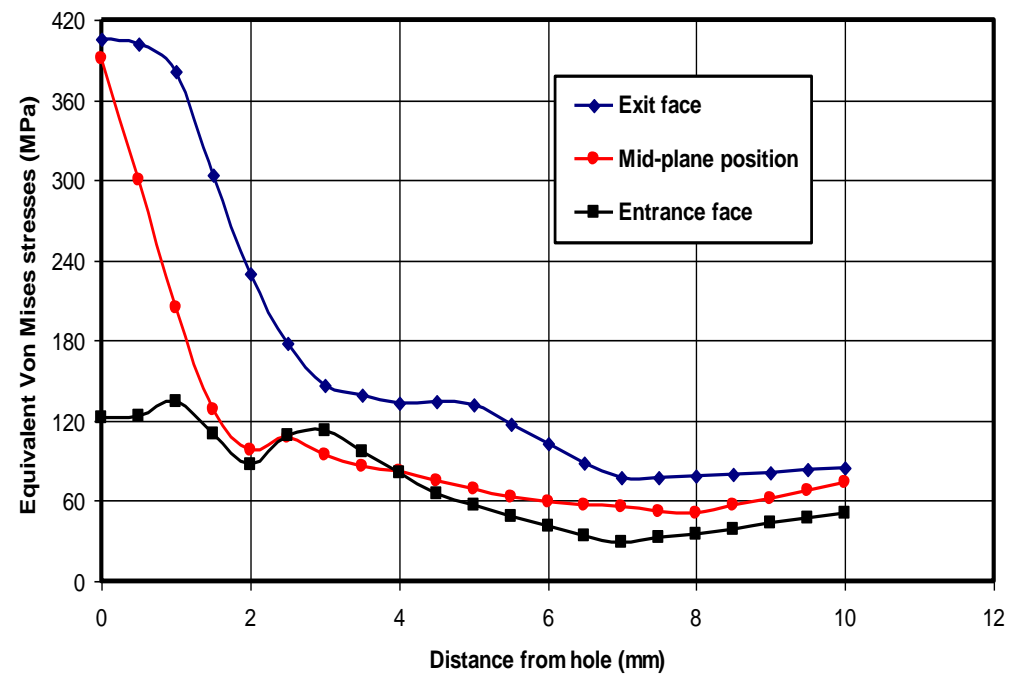

Figure 5: Von-Mises equivalent stress along the path of growth.

Tangential residual stress distribution established from the finite element analysis shows that it not uniform throughout the thickness of a cold expanded hole of finite plate (Fig. 7). Significant compressive tangential residual stress is produced between tapered pin and hole. This shows beneficial effect of induced friction between aluminium alloy plate and steel pin at free surface of hole. The evolution of tangential residuals stresses throughout thickness can be described by a polynomial equation shown above.

$$
\sigma_{\theta \theta}=15.55 \times a^{2}-148.45 \times a-99.1
$$

"a" present parameter variation of the thickness from the entrance face to the exit face 


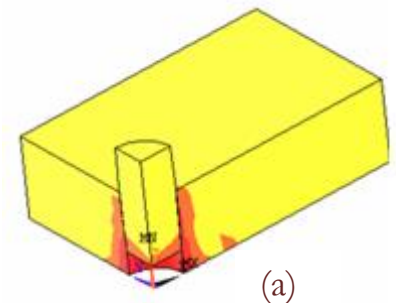

(a)

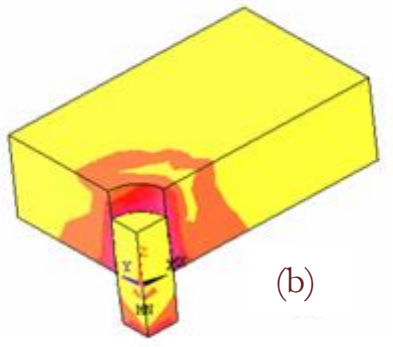

(b)

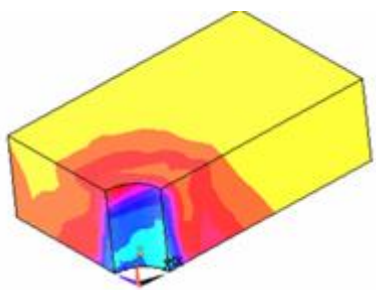

Figure 6: Distribution of Von-Mises equivalent stress around the hole.

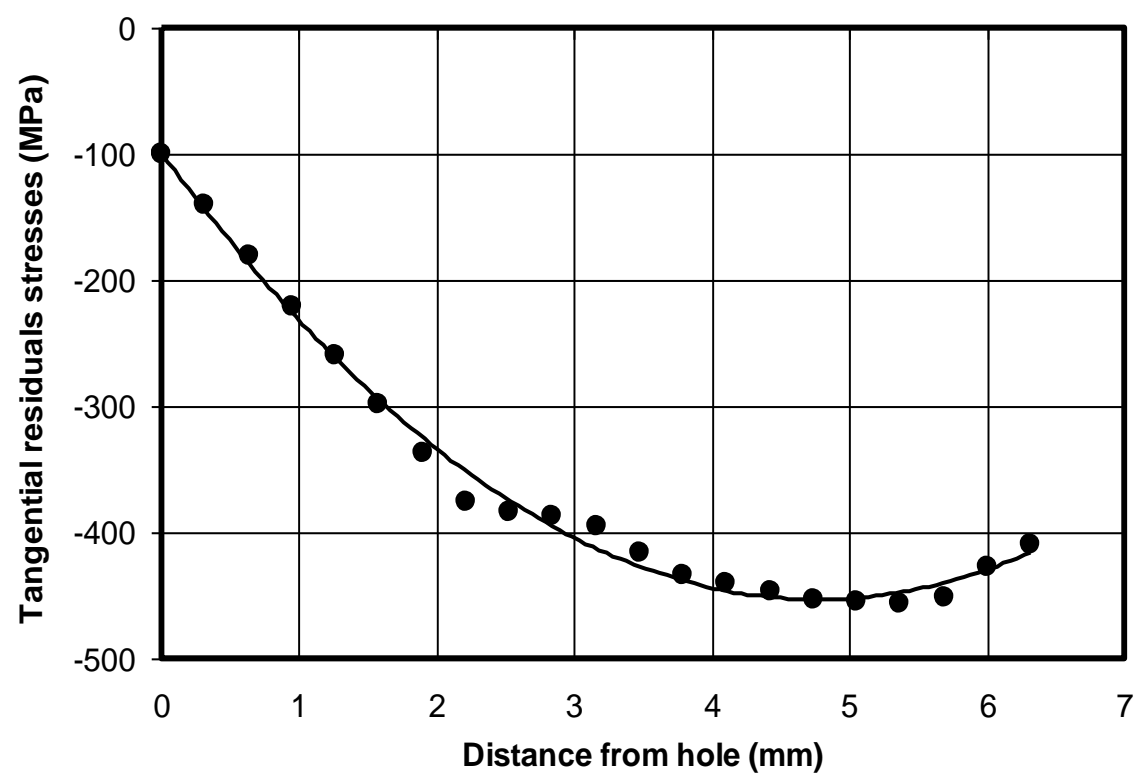

Figure 7: Tangential residual stress throughout thickness of plate

\section{INFLUENCE OF COMPRESSive RESIDUAL STRESS ON FATIGUE CRACK INITIATION}

$\mathrm{I}$

$\mathrm{n}$ order to evaluate the fatigue crack initiation life, local strain approach was applied by several researchers cited above. In fatigue case and at the notch tip, local strains are obtained by using the Neuber's rule or Glinka [43] expressed in following form:

$$
\frac{\left(K_{f} \cdot \Delta \sigma_{a}\right)^{2}}{4 E}=\frac{\Delta \sigma \cdot \Delta \varepsilon}{2}
$$

where " $\sigma_{a}$ " is the applied stress and " $\sigma$ " and " $\varepsilon$ " are the resulting local stress and strain values corrected for the notch effect.

The fatigue notch factor, $\left(\mathrm{K}_{\mathrm{f}}\right)$, is essentially the $\mathrm{K}_{\mathrm{t}}$ value corrected to account for the notch sensitivity for the given material [44]. It is determined as follows: 


$$
K_{f}=1.0+\left(\frac{K_{f}-1.0}{1.0+(\alpha / r)}\right)
$$

where " $\alpha$ " is an empirically determined material constant [45] and $\mathrm{r}$ is the notch root radius.

In Glinka's approach the local strains and stresses should represent energy equivalence as compared the remote loading conditions, leading to the following equation:

$$
\frac{\left(K_{f} \cdot \Delta \sigma_{a}\right)^{2}}{2 E}=\frac{\Delta \sigma^{2}}{4 E}+\frac{\Delta \sigma}{n^{\prime}+1}\left(\frac{\Delta \sigma}{2 K^{\prime}}\right)^{\frac{1}{n^{\prime}}}
$$

In this equation " $K$ '” and " $n$ " " correspond to the material's cyclic hardening law.

The local strains were determined by coupling equation (2) and (4), given local strain range in function of local stress range named cyclic stress-strain (equation 5).

$$
\frac{\Delta \varepsilon}{2}=\frac{\Delta \sigma}{2 E}+\left(\frac{\Delta \sigma}{2 K^{\prime}}\right)^{\frac{1}{n^{\prime}}}
$$

In 1910, Basquin [46] observed that stress-life (S-N) data could be plotted linearly on a log-log scale and expressed by:

$$
\frac{\Delta \varepsilon_{e}}{2}=\frac{\Delta \sigma}{2 E}=\frac{\sigma_{f}^{\prime}}{2 E}\left(2 N_{f}\right)^{b}
$$

Manson and Coffin [47] [41], working independently, found that plastic strain-life data $(\varepsilon \mathrm{p}-\mathrm{N})$ could be linearized in log$\log$ co-ordinates.

$$
\frac{\Delta \varepsilon_{p}}{2}=\left(\frac{\Delta \sigma}{2 K^{\prime}}\right)^{\frac{1}{n^{\prime}}}=\varepsilon_{f}^{\prime}\left(2 N_{f}\right)^{c}
$$

The relationship between total strain amplitude, $\Delta \varepsilon / 2$ and life to failure, $2 N_{f}$, can be expressed in the form [25]:

$$
\frac{\Delta \varepsilon}{2}=\frac{\sigma_{f}^{\prime}}{2 E}\left(2 N_{f}\right)^{b}+\varepsilon_{f}^{\prime}\left(2 N_{f}\right)^{c}
$$

where " $\sigma_{f}^{\prime}$ " is the fatigue strength coefficient; " $b$ " is the fatigue strength exponent, " $\varepsilon_{f}^{\prime}$ " is the fatigue ductility, " $c$ " is the fatigue ductility exponent.

The strain-life based crack initiation analysis method to predict crack initiation life is incorporated in AFGROW code [48]. Cyclic strain-life parameters used in fatigue crack initiation analysis for investigated material are given in Table 2.

\begin{tabular}{ccccccc}
\hline$\sigma_{f}^{\prime}$ & $\varepsilon_{f}^{\prime}$ & $b$ & $c$ & $K_{f}$ & $K^{\prime}$ & $n^{\prime}$ \\
1013.53 & 0.21 & -0.21 & -0.52 & $0.5 \times 10^{-4}$ & 786 & 0.09 \\
\hline
\end{tabular}

Table 2: Cyclic strain life properties of 2024 T351 Aluminium alloy.

The effect of expansion is illustrated in Fig. 8. The 4.6\% degree of expansion is applied to a hole. The applied spectrum is with constant amplitude loading considering four stress ratios are applied varying from 0.1 to 0.54 . The maximum stress used in this investigation was $240 \mathrm{MPa}$. The initiation lives are predicted for crack initiation length equal to $0.5 \mathrm{~mm}$. Others researchers have taken the initiation of the crack is equivalent to $10^{5}$ cycles [6, 49-51]. It is noticed from Fig. 5 that the expansion process improves initiation fatigue life due to the existence of compressive residual stresses on the side of 
the hole. The mean residual stress field is applied. This field of stresses tends to increase the initiation fatigue life as shown in Fig. 8 comparatively to drilled hole in plate without residual stress field.

Indeed, the increase in the hole diameter reduces the stresses concentration factor $K_{\ell}$ [44]. The concentration factor is equal to 3 for drilled hole and decreases to 1.75 where " $\mathrm{Kt}$ " is defined as $K_{t}=\left(\sigma_{\max }+\sigma_{r e s} / \sigma_{n o m}\right)$. The ratio of initiation life $R I=\left(N_{i-\operatorname{Res}} / N_{i-W-R e s}\right)$ depends on stress ratio. This ratio increases with increasing of stress ratio and vary from 3.22 to 3.85. Also, the increasing in stress ratio increases the initiation life [19] that is attributed to reduction in amplitude loading. The predicted results have exponential evolution and are given by equation 9 and 10 respectively for expanded hole and drilled hole (without residual stress). It concluded that initiation life is improved by the presence of compressive residual around the hole.

$$
\begin{aligned}
& N_{i_{-} \operatorname{Re} s}=3.07 \times 10^{4} \cdot \operatorname{Exp}(5.75 \times R) \\
& N_{i_{-} W-e s}=1.01 \times 10^{4} \cdot \operatorname{Exp}(5.38 \times R)
\end{aligned}
$$

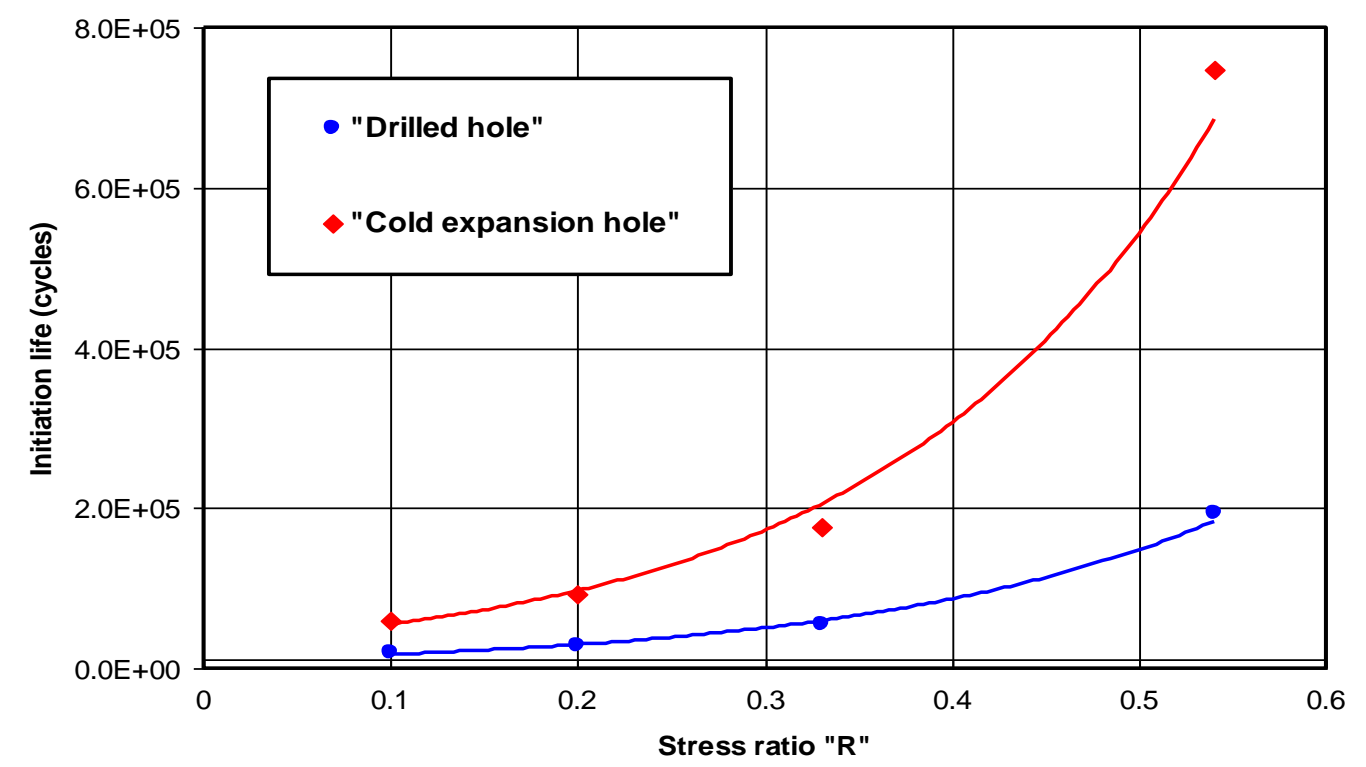

Figure 8: Effect of cold expansion of hole on initiation fatigue life

\section{CONCLUSION}

he aim of this work is to investigate the effect of residual stress induced by cold expansion in drilled hole on the crack initiation of $2024 \mathrm{~T} 351 \mathrm{Al}$-alloy plate. Also the following conclusions can be drawn from the analysis:

- A 3D finite element simulation of cold expansion using a tapered pin has shown that the tangential residual stress is not uniform at the hole edge through the plate thickness.

- The maximum compressive tangential residual stress occurs at the hole edge near exit face and the mid-plane. Also the smallest compressive residual stress occurs at the entrance face.

- In the present investigation we have considered that crack is initiated with the same length through the thickness, so the mean residual stress field due to cold expansion is applied.

- Fatigue initiation life is improved by the presence of compressive residual stress around the hole comparatively to drilled hole without residual stress. The percentage in this improving varies from 3.22 to 3.85 . Additionally, the effect of stress ratio on initiation life is highlighted. 


\section{REFERENCES}

[1] Wanhill, R., Barter, S. and Molent, L. (2014). Fatigue crack growth failure analyses in metallic aircraft components. $11^{\text {th }}$ International Fatigue Congress 2014, pp. 2-7, Melbourne, Australia.

[2] Rodopoulos, C.A., Curtis, S.A., de los Rios, E.R. and Solis Romero, J. (2004), Optimisation of the fatigue resistance of 2024-T351 aluminium alloys by controlled shot peening-methodology, results and analysis. International Journal of Fatigue 26(8), pp. 849-856. DOI: 10.1016/j.ijfatigue.2004.01.003.

[3] Huang, S., Zhou, J.Z. , Sheng, J. , Luo, K.Y. , Lu, J.Z., Xu, Z.C. and Meng, X.K. (2013). Effects of laser peening with different cover age areas on fatigue crack growth properties of 6061-6 aluminum alloy, International Journal of Fatigue 47, pp. 292-299. DOI: 10.1016/j.ijfatigue.2012.09.010.

[4] Sheng, J., Huang, S., Zhou, J.Z., Lu, J.Z., Xu, S.Q. and Zhang, H.F. (2016). Effect of laser peening with different energies on fatigue fracture evolution of 6061-T6 aluminum alloy. Optics \& Laser Technology, 77, pp. 169-176.

DOI: $10.1016 /$ j.optlastec.2015.09.008

[5] Ren, X.D., Zhan, Q.B., Yang, H.M., Daic, F.Z., Cui, Y., Sun, G.F. and Ruan, L. (2013). The effects of residual stress on fatigue behavior and crack propagation from laser shock processing-worked hole, Materials \& Design 44, pp. 149154. DOI: $10.1016 /$ j.matdes.2012.07.024

[6] Semari, Z., Aid, A. and Benhamena, A. (2013). Effect of residual stresses induced by cold expansion on the crack growth in 6082 aluminum alloy. Engineering Fracture Mechanics, 99, pp. 159-68.

DOI:10.1016/j.engfracmech.2012.12.003

[7] Yucan, F., Ende, G., Honghua, S., Jiuhua, X. and Renzheng, L. (2015). Cold expansion technology of connection holes in aircraft structures: A review and prospect. Chinese Journal of Aeronautics, 28(4), pp. 961-973.

DOI:10.1016/j.cja.2015.05.006

[8] Chakherlou, T.N., Taghizadeh, H. and Aghdam, A.B. (2013). Experimental and numerical comparison of cold expansion and interference fit methods in improving fatigue life of holed plate in double shear lap joints. Aerospace Science Technology, 29(1), pp. 351-362. DOI: 10.1016/j.ast.2013.04.006.

[9] Yongshou, L., Jun, L. and Zhufeng, Y. (2010). Finite element method and experimental investigation on the residual stress fields and fatigue performance of cold expansion hole. Materials \& Design, 31(3), pp. 1208-1215.

DOI: 10.1016/j.matdes.2009.09.031.

[10] Glinka, G. (1987). Residual stress in fatigue and fracture: Theoretical analyses and experiments. In Niku-Lari A., Editor, Advances in Surfaces Treatments, pp. 413-454. Pergamon Press, Residual stresses, 4.

[11] Topper, T. H., Wetzel, R. M. and Morrow, J. (1969). Neuber's rule applied to fatigue of notched specimens, Journal of Materials, 4(1), pp. 200-209.

[12] Glinka, G. (1985). A notch stress-strain analysis approach to fracture crack growth, Engineering Fracture Mechanics, 21(2), pp. 245-261. DOI: 10.1016/0013-7944(85)90014-1.

[13] Truchon, M. (1982). Application of low-cycle fatigue test results to crack initiation from notches, low-cycle fatigue and life prediction. ASTM STP 770, C. Amzallag, B. N. Leis, and P. Rabbe, (Eds.), American Society for Testing and Materials, pp. 254-268.

[14] Zheng, X. (2001). On some basic problems of fatigue research in engineering, International Journal of Fatigue, 23, pp. 751-766. DOI: 10.1016/S0142-1123(01)00040-8.

[15] Zheng, M., Niemi, E. and Zheng, X. (1997). An energetic approach for predict fatigue crack initiation life of LY 12 CZ aluminum and $16 \mathrm{Mn}$ steel, Theoretical Applied Fracture Mechanics, 26, pp. 23-38.

DOI: 10.1016/S0167-8442(96)00030-4.

[16] McMaster, F.J. and Smith, D.J. (2001). Predictions of fatigue crack growth in aluminium alloy 2024-T351 using constraint factors. International Journal of Fatigue, 23, pp. 93-101. DOI: 10.1016/S0142-1123(01)00134-7.

[17] Rodopoulos, C.A., Choi, J.H., De Los Rios, E.R. and Yates, J.R. (2004). Stress ratio and the fatigue damage map-Part II: The 2024-T351 Al-alloy, International Journal of Fatigue, 26, pp. 747-752.

DOI:10.1016/j.ijfatigue.2003.10.018

[18] Fujczak, R.R. (1984). Effects of R-ratio on crack initiation at external discontinuities in auto frettaged cylinders, Experimental Mechanics, 9, pp. 122-128. DOI: 10.1007/BF02324994.

[19] Ranganathan, N., Aldroe, H., Lacroix, F., Chalon, F., Leroy, R. and Tougui, A. (2011). Fatigue crack initiation at a notch. International Journal of Fatigue, 33, pp. 492-499. DOI: 10.1016/j.ijfatigue.2010.09.0071.

[20] Amrouche, A., Mesmacque, G. and Garcia, S. (2003). Cold expansion effect on the initiation and the propagation of the fatigue crack. International Journal of Fatigue, 25(9-11), pp. 949-954. DOI: 10.1016/S0142-1123(03)00127-0. 
[21] Zhao, Q., Liu, F. and Huang, H. (2014). Study on the residual stress and fatigue performance of cold expansion hole on 7050-T7451. Advanced Materials Research, 1004-1005, pp. 1299-1304.

DOI: 10.4028/www.scientific.net/AMR.1004-1005.1299.

[22] Gopalakrishna, H.D., Narasimha Murthy, H.N., Krishna, M., Vinod, M.S. and Suresh, A.V. (2010). Cold expansion of holes and resulting fatigue life enhancement and residual stresses in Al 2024 T3 alloy - An experimental study. Engineering Failure Analysis, 17, pp. 361-368. DOI: 10.1016/j.engfailanal.2009.08.002.

[23] Chandawanich N. and Sharpe W. (1979). An experimental study of fatigue crack growth initiation and growth from cold worked holes, Engineering Fracture Mechanics, 11, pp. 609-920. DOI: 10.1016/0013-7944(79)90122-X.

[24] Su, M., Amrouche, A., Mesmacque, G. and Benseddiq, N. (2008). Numerical study of double cold expansion of the hole at crack tip and the influence on the residual stresses field. Computational Materials Sciences, 41, pp. 350-355.

DOI: 10.1016/j.commatsci.2007.04.022.

[25] Warner, J.J., Clark, P.N. and Hoeppner, D.W. (2014). Cold expansion effects on cracked fastener holes under constant amplitude and spectrum loading in the 2024-T351 aluminum alloy. International Journal of Fatigue, 68, pp. 209-216. DOI: 10.1016/j.ijfatigue.2014.05.002.

[26] Liu, Y.S, Gou, B.W., Shao, X.J, Jiang, Z.F. and Yue Z.F. (2010). Effect of thickness on residual stress fields of cold expansion hole. Advanced Materials Research, 97-101, pp. 601-604.

DOI: 10.4028/www.scientific.net/AMR.97-101.601.

[27] Chakherlou, T.N. and Vogwell, J. (2003). The effect of cold expansion on improving the fatigue life of fastener holes. Engineering Failure Analysis, 10, pp. 13-24. DOI: 10.1016/S1350-6307(02)00028-6.

[28] Liu, J., Wu, H., Yang, J. and Yue, Z. (2013). Effect of edge distance ratio on residual stresses induced by cold expansion and fatigue life of TC4 plates. Engineering Fracture Mechanics, 109, pp. 130-137.

DOI:10.1016/j.engfracmech.2013.05.012.

[29] Smith, K.N., Watson, P. and Topper, T.H. (1970). A stress-strain function for the fatigue of metals. Journal Materials, 15, pp. 767-778. Available at: https://www.researchgate.net/publication/269929853_14_ Smith_K_N_Watson_P_and_Topper_T_H_'A_StressStrain_Function_for_the_Fatigue_of_Metals_nl_of_Marls_1M LSA_5_4_767-778_Dee_1070.

[30] Wang, C.H. and Brown, M.W. (1993). A path-independent parameter for fatigue under proportional and nonproportional loading. Fracture of Engineering Materials \& Structures, 16(12), pp. 1285-1297.

DOI: $10.1111 /$ j.1460-2695.1993.tb00739.x.

[31] Kurhade, R.S., Wadegaonkar, A.P. and Pradhan, B. (2004). Finite element analysis of effects of strain hardening rate on cold expansion of fastener holes. Available at : www.ansys.com/-/media/ansys/.../2004-int-ansys-conf-164.pdf

[32] Liu, J., Shao, X.J., Liu, Y.S. and Yue, Z.F. (2009). Effect of cold expansion on fatigue performance of open holes. Engineering Fracture Mechanics, 477, pp. 271-276. DOI: 10.1016/j.msea.2007.05.034.

[33] ANSYS Release 11.0 Documentation, ANSYS Inc., 2008.

[34] Brandts, J., Korotov, S. and Krizek, M. (2011). A geometric toolbox for tetrahedral finite element partitions. In book: Efficient preconditioned solution methods for elliptic PDEs (2011), pp. 103-122.

DOI:10.2174/978160805291211101010103.

[35] Duarte, C.A., Babuska, I. and Oden, J.T. (2000). Generalized finite element methods for three dimensional structural mechanics problems. Computers \& Structures, 77(2), pp. 215-232.

DOI: 10.1016/S0045-7949(99)00211-4.

[36] Oñate, E., Rojek, J., Taylor, R.L. and Zienkiewicz, O.C. (2004). Finite calculus formulation for incompressible solids using linear triangles and tetrahedral. Int. J. Numer. Meth. Engng, 59, pp. 1473-1500. DOI: 10.1002/nme.922.

[37] Persson, P.O. and Peraire, J., Curved mesh generation and mesh refinement using lagrangian solid mechanics. American Institute of Aeronautics and Astronautics. Proc. of the 47th AIAA Aerospace Sciences Meeting and Exhibit, 2009. Available at: https://pubarchive.lbl.gov/islandora/object/ir\%3A152677.

[38] Payen, D. J. and Bathe, K.-J. (2011). Improved stresses for the 4-node tetrahedral element. Computers and Structures, 89, pp. 1265-1273. DOI: 10.1016/j.compstruc.2011.02.009.

[39] Okada, H. and Kamibeppu, T. (2005). A virtual crack closure-integral method (VCCM) for three-dimensional crack problems using linear tetrahedral finite elements. CMES, 10(3), pp. 229-238, Tech Science Press. Available at: https://www.techscience.com/doi/10.3970/cmes.2005.010.229.pdf

[40] Farhangdoost, Kh. and Hosseini, A. (2011). The effect of mandrel speed upon the residual stress distribution around cold expanded hole. Procedia Engineering, 10, pp. 2184-2189. DOI: 10.1016/j.proeng.2011.04.360.

[41] Nigrelli, V. and Pasta, S. (2008). Finite-element simulation of residual stress induced by split-sleeve cold-expansion process of holes. Journal of Materials Processing Technology, 205, pp. 290-296.

DOI:10.1016/j.jmatprotec.2007.11.207. 
[42] Houghton, S.J. (2010). Finite analysis of the cold expansion of aircraft fastner holes, DTA Report 295.

[43] Neuber, H. (1960). Theory of stress concentration for shear-strained prismatical bodies with arbitrary nonlinear stress-strain law. Trans. ASME, Journal of Applied Mechanics, pp. 544-550.

[44] Peterson, R.E. (1974). Stress Concentration Factors, John Wiley and Sons.

[45] Hall, L.R., Shah, R.C. and Engstorn, W.L. (1974). Fracture and fatigue crack growth behavior of surface flaws originating at fastener holes. AFFDL-TR-74-47, Air Force Flight Dynamics Lab, Ohio.

[46] Basquin, O.H. (1910). The exponential law of endurance tests, Proceedings of American Society of Testing and Materials, 10 Part II, pp. 625-630.

[47] Coffin, L.F. (1954). A study of effects of cyclic thermal stresses on a ductile metal, Transactions of the ASME, 76, pp. 931-950.

[48] Harter, J.A. (2006). AFGROW users guide and technical manual: AFGROW for Windows 2K/XP. Version 4.0011.14, Air Force Research Laboratory.

[49] Man, S. (2005). Etude de l'influence et de l'optimisation du degré d'expansion à froid dans les mécanismes de réamorçage d'une fissure: étude numérique et expérimentale. Doctoral Thesis. University of Sciences and Technologies of Lille; France.

[50] Todoroki, A. and Kobayashi H. (1991). Prediction of fatigue crack growth rate in residual stress fields. Key Engineering Materials: Fracture Strength, 367, pp. 51-62. DOI:10.4028/www.scientific.net/KEM.51-52.367.

[51] Nigrelli, V. and Pasta, S. (2008). Finite-element simulation of residual stress induced by split-sleeve cold expansion process of holes. Journal of Materials Processing Technology, 205, pp. 290-296.

DOI:10.1016/j.jmatprotec.2007.11.207. 